\title{
Diffusion in garnet: a review
}

\author{
Bowen $\mathrm{Li}^{1,2} \cdot$ Jianhua $\mathrm{Ge}^{1,2} \cdot$ Baohua Zhang ${ }^{1}$ (i)
}

Received: 31 March 2017/Revised: 15 May 2017/ Accepted: 9 June 2017/Published online: 21 June 2017

(c) The Author(s) 2017. This article is an open access publication

\begin{abstract}
With improvements on high-pressure experimental techniques in multi-anvil apparatus and the development of new analytical tools, major progress has been made on diffusion in garnets in the past several decades. The data obtained in the experimental determination of diffusion coefficients in garnets are of fundamental importance for diffusion modeling and timescales of geological and planetary processes. In this review, we have compiled experimental data on self-diffusion ( $\mathrm{Si}, \mathrm{O}$, cations), trace element diffusion ( $\mathrm{Li}, \mathrm{Y}, \mathrm{Ga}, \mathrm{Cr}, \mathrm{Sr}, \mathrm{REEs})$, and interdiffusion $(\mathrm{Ca}-$ $\mathrm{Fe} / \mathrm{Mg}, \mathrm{Si}-\mathrm{Al}$ ) in garnet in the light of new advances and recent applications. In addition, some empirical relationships among diffusion parameters (pre-exponential factor $D_{0}$, activation energy $E$, ionic radius) are also discussed. We hope that this review can provide a useful data digest and guide to future study of diffusion in garnet.
\end{abstract}

Keywords High temperature and high pressure .

Diffusion · Garnet · Point defects

\section{Introduction}

Diffusion is believed to be the rate-determining step in many processes of interest to materials science, physical metallurgy, geosciences, and many other areas. Solid state

Baohua Zhang

zhangbaohua@vip.gyig.ac.cn

1 Key Laboratory for High-Temperature and High-Pressure Study of the Earth's Interior, Institute of Geochemistry, Chinese Academy of Sciences, Guiyang 550081, China

2 University of Chinese Academy of Sciences, Beijing 100049, China diffusion of cations in silicate minerals has long attracted theoretical attention, extensive efforts focused on experimental and empirical determination of rates, and widespread petrologic application (Ganguly 2002; Watson and Baxter 2007; Chakraborty 2008; Brady and Cherniak 2010). Comprehensive understanding and proper application of experimental diffusion-rate data require precise knowledge of cation and rare earth element (REE) diffusion kinetics and mechanisms across the widest possible span of temperatures, pressures, oxygen fugacities, and host-garnet compositions.

Garnet is an important rock-forming mineral of various magmatic, metamorphic, and metasomatic rocks, crystallizing in many different lithologies and at various pressuretemperature (P-T) conditions in the Earth's crust and mantle. Garnets are nesosilicates having the general formula $X_{3} Y_{2}\left(Z_{4}\right)_{3}$ (space group $I a \overline{3} d$ ), and displaying dodecahedral $(X)$, octahedral $(Y)$, and tetrahedral $(Z)$ crystallographic sites. This unique feature makes the garnet structure flexible in accommodating a variety of cations with different ionic radii. In Earth-relevant compositions, garnet is mostly present as a non-ideal solid solution where $\mathrm{X}=\mathrm{Ca}^{2+}, \mathrm{Mg}^{2+}, \mathrm{Fe}^{2+}$, $\mathrm{Mn}^{2+}$, etc.; $\mathrm{Y}=\mathrm{Al}^{3+}, \mathrm{Fe}^{3+}, \mathrm{Cr}^{3+}$, etc.; $\mathrm{Z}=\mathrm{Si}^{4+}, \mathrm{As}^{4+}$, $\mathrm{V}^{4+}$, etc. In the shallow part of the upper mantle, silicate garnets are considered to comprise only $\sim 15 \mathrm{vol} \%$. However, due to pyroxene progressive transformation into garnet with increasing depth, its volume fraction rises to $40 \mathrm{vol} \%$ for pyrolite composition, and up to $60 \mathrm{vol} \%$ for piclogite composition (Irifune and Ringwood 1987) in the Earth's mantle transition zone. Therefore, knowledge of diffusion rate in garnet allows constraints to be placed on detailed records of geological processes, timescales, and thermodynamic conditions in many natural contexts where mass transport is dominated by solid state diffusive processes. 
Diffusion in garnet is of special interest owing to its common presence in rocks of the deep crust and upper mantle, its wide range of major- and trace-element composition, and the broad span of temperatures over which appreciable modification of its compositional zoning can occur (Chakraborty and Ganguly 1992). Preservation and modification of compositional zoning have been used widely to obtain timescales of various processes (e.g., cooling rates, exhumation rates) and as records of tectonic-, reaction-, deformation-, and fluid-flow histories (Watson and Baxter 2007; Ganguly 2010; Mueller et al. 2010). A key parameter in such analyses is the relevant diffusion coefficient in various garnet compositions. A significant body of experimental diffusion data now exists in the literature, and partial reviews for systems and materials of geological interest are available for diffusion in garnet (Freer 1981; Brady 1995; Ganguly 2002, 2010; Béjina et al. 2003; Watson and Baxter 2007; Chakraborty 2008, 2010; Brady and Cherniak 2010; Cherniak and Dimanov 2010). The primary purposes of this review are to critically summarize the available experimental and semiempirical data on diffusion (i.e., self-diffusion, chemical diffusion, impurity diffusion, and interdiffusion) in garnet, and discuss illustrative applications to a wide spectrum of problems in petrology, geochemistry, geodynamics, and other fields. We hope that this review will assist researchers in quickly finding the data they need. For the sake of completeness, we start with a simple introduction about fundamentals of diffusion and experimental techniques and then discuss the available data and its applications. Finally, some empirical relationships and geological applications of experimental diffusion data are discussed.

\section{Basic concepts and experimental measurement techniques}

\subsection{Nomenclature of diffusion coefficients}

There are many types of diffusion in nature and experimental studies. Because diffusion involves a diffusing species in diffusion medium, it can be classified based on either the diffusion medium or the diffusing species. When considering the diffusion medium, thermally activated diffusion may be classified as volume diffusion or grainboundary diffusion (Chakraborty 2008). Volume diffusion (also called lattice diffusion) refers to atomic diffusion within a crystalline lattice. In volume diffusion, the diffusion medium can be either isotropic or anisotropic. Both melts (and glasses) and isometric minerals are isotropic diffusion media; non-isometric minerals are generally anisotropic diffusion media (although in some cases, the dependence of diffusivities on the direction is weak).
Grain-boundary diffusion is diffusion along interphase interfaces, including mineral-fluid interfaces (or surfaces), interfaces between the same mineral, and those between different minerals.

When considering differences in the diffusing species, diffusion can be classified as self-diffusion, tracer diffusion, interdiffusion coefficient, or chemical diffusion, which can be further distinguished as trace element-, binary-, multispecies-, multicomponent-, or effective binary diffusion. Detailed definitions of various kinds of diffusion coefficient can be found elsewhere (Shewmon 1963; Ganguly 2002, 2010; Mehrer 2007; Zhang 2010).

\subsection{Diffusion mechanism}

When the random-walk model is expanded to take into account the real structures of solids, it becomes apparent that diffusion in crystals is dependent upon point defect concentrations. Various types of point defects (vacancy, interstitial, and substitutional defects) can present thermally in many materials including metal, ionic, and molecular crystals (Mehrer 2007; Zhang 2017). Several atomic mechanisms of diffusion in crystals have been identified and are catalogued: vacancy-, interstitial-, divacancy-, interstitialcy-, and interstitial-substitutional exchange mechanisms. Dislocations, grain/phase boundaries, and free surfaces are other types of defects of crystalline solids. They can act as diffusion short circuits, because the mobility of atoms along such defects is usually much higher than in the lattice. However, by far the most prominent mechanisms are the vacancy mechanism (i.e. exchange of position between atoms and lattice vacancies) and the interstitial mechanism (i.e. migration of atoms through interstitial sites). For more comprehensive understanding of the field of point defects and the diffusion mechanisms in crystals, the reader is referred to the textbooks (e.g., Shewmon 1963; Mehrer 2007; Tilley 2008).

\subsection{Influencing factors of diffusion coefficient}

In general, more than one point defect species may be present in a crystal at any temperature, and the amount of matter transported by diffusion will depend upon the number of each defect type present. Diffusion coefficients in any real system are therefore controlled by a number of factors, which may be broadly divided into external and internal properties of the crystal. The former includes temperature, pressure, water (fugacity), oxygen fugacity $\left(f \mathrm{O}_{2}\right)$, and sometimes the state of strain/deformation. The latter includes chemical composition, crystallinity, defect concentration, and depending upon the nature of the specimen, anisotropy (for single crystals) or porosity (for polycrystalline material). 


\subsubsection{Effect of temperature and pressure}

The temperature and pressure dependence of diffusion coefficients can be combined to yield an Arrhenius equation that is obeyed at most conditions:

$D=D_{0} \exp \left(-\frac{\Delta E+P \Delta V}{R T}\right)$

where $D$ is the measured diffusion coefficient, $D_{0}$ is a constant term referred to as the pre-exponential factor, $\Delta E$ is the activation energy of diffusion, $R$ is the gas constant and $T$ is the temperature $(\mathrm{K})$, and $\Delta V$ is the activation volume, which can be either positive (leading to a decrease of $D$ with increasing $P(\mathrm{GPa})$ ) or negative (leading to an increase of $D$ with increasing $P$ ).

Although the effect of $P$ on $D$ is small compared to the temperature dependency, this effect could become significant under the enormous pressure conditions in the Earth's interior because pressure can vary widely from the surface to deep Earth. It is worth noting that, due to the technical difficulties of performing high-pressure diffusion experiments in the laboratory, such pressure dependence has not been investigated well for many systems. This remains an important task for experimentalists in the future.

\subsubsection{Oxygen fugacity}

In the Earth's interior, for most minerals and rocks containing variable valence elements, such as iron, $f_{2}$ is expected to influence the diffusion property by changing the defect concentrations through change of oxidation state of multivalent elements and of the defect sites in the structure. It should be noted that $f \mathrm{O}_{2}$ affects the diffusion coefficient not just of $\mathrm{Fe}$, but also that of other cations. Previous experimental investigations (Chakraborty et al. 1994; Dohmen and Chakraborty 2007) have demonstrated that the dominant diffusion mechanism can change as a function of $\mathrm{Fe}$ concentration and $f \mathrm{O}_{2}$. Vacancy diffusion plays the dominant role at $f \mathrm{O}_{2}$ above the minimum whereas interstitial diffusion plays the dominant role at lower $f \mathrm{O}_{2}$.

\subsubsection{Water}

The presence of water in nominally anhydrous minerals (NAMs), even at very low concentrations, may significantly affect transport properties involving ionic diffusion in minerals. A summary of the available experimental data on the effect of water on diffusion in mineralogically important systems may be found in Cherniak (1993). She showed that water may not play a significant role in the interdiffusion process that involves only a simple exchange between cations of the same charge. On the contrary, recent studies have revealed significant enhancement by $\mathrm{H}_{2} \mathrm{O}$ of
$\mathrm{Fe}-\mathrm{Mg}$ interdiffusion in olivine (Chakraborty 1997; Wang et al. 2004; Hier-Majumder et al. 2005). The enhancement of diffusion rate has been attributed to the entry of water into the lattice, and consequent changes in point defect concentrations (cation vacancies). Therefore, it seems that the effect of $\mathrm{H}_{2} \mathrm{O}$ on lattice diffusion of cations in deepseated mantle phases is quite different, perhaps because the available lattice solution mechanisms for $\mathrm{H}$-bearing species are different. In the future, the effect of $\mathrm{H}_{2} \mathrm{O}$ on diffusion kinetics needs to be carefully investigated so the experimental data can be applied to natural systems in a meaningful way. Our understanding of the problem at the present stage is sketchy at best.

\subsubsection{Composition}

Diffusion of a component depends on major element composition, and occasionally also on minor element composition. The compositional effects on diffusivities are very complicated in Earth materials; in most instances, an exponential dependence of composition on diffusivity may be found. For example, Dohmen and Chakraborty (2007) showed that the $\mathrm{Fe}-\mathrm{Mg}$ interdiffusion in olivine increases exponentially with the mole fraction of fayalite $(\ln D$ is linear to $X_{\mathrm{Fa}}$ ). Diffusion of the hydrous component in orthopyroxenes depends strongly on the composition of orthopyroxenes (Farver 2010). If the aforementioned influencing factors $\left(T, P, f \mathrm{O}_{2}, C_{\mathrm{H} 2 \mathrm{O}}, X_{\mathrm{Fe}}\right)$ are simultaneously taken into account, the diffusion coefficient can be rewritten (Jaoul et al. 1995; Dohmen and Chakraborty 2007; Farver 2010):

$D=D_{0}\left(f_{\mathrm{O}_{2}}\right)^{n}\left(C_{\mathrm{H}_{2} \mathrm{O}}\right)^{r} X^{p} \exp \left(-\frac{\Delta E+\alpha X+P \Delta V}{R T}\right)$

where $n, r$, and $p$ are constants, and $\alpha$ is a parameter related to the activation energy. In addition to the abovementioned issues, other affecting factors including crystallographic orientation (anisotropy), isotope effect, stress, and deformation, have been reviewed and discussed in detail by many researchers (Ganguly 2002; Mehrer 2007; Chakraborty 2008; Zhang 2010, 2017).

\subsection{Experimental techniques}

Most diffusion experiments relevant to mantle minerals have been performed under high pressure and high temperature and controlled thermodynamic conditions (e.g., $f \mathrm{O}_{2}$, water content, silica activity, etc.), by employing a solid-media apparatus of piston-cylinder or multi-anvil press of the Kawai/DIA-type. The most common methods for studying diffusion in simple solids involve the diffusion couple method and the application of radiotracers (thinsource diffusion) to prepared surfaces before high 
temperature annealing and subsequent sectioning to deduce the diffusion profile. Other indirect methods are not discussed here (for details see Watson and Dohmen 2010 and Cherniak et al. 2010). Depending on the properties of the diffusion medium and the nature of the element, the resultant diffusion profiles of a given element are usually short because of limited laboratory time scales (usually less than 1 week) and accessible P-T conditions. Currently, precise analytical techniques include secondary ion mass spectrometry (SIMS), Rutherford backscattering spectrometry (RBS), nuclear reaction analysis (NRA), elastic recoil detection (ERD) and auger electron spectroscopy (AES), synchrotron X-ray fluorescence (SRXRF), electron microprobe analysis (EPMA), and laser-ablation inductively coupled mass spectrometry (LA-ICP-MS) (for details see Cherniak et al. 2010).

Besides the determination of diffusion rates in garnet by high-temperature and high-pressure experiment, an alternative approach is computer simulation through molecular dynamics or first-principle calculation. Over the past several decades, studies using atomistic methods have demonstrated that reliable values can be calculated for defect formation and migration energies. It is worth noting that Wright et al. (1994) first used computer simulation methods to model the structure and energetics of the hydrogarnet defect in grossular. Recently, similar studies have been reported by Pigott et al. (2015) for $\mathrm{MgSiO}_{3}$ majorite up to $25 \mathrm{GPa}$ employing both classical atomistic simulations and complementary first-principles calculations. However, owing to the complexity of the structure and composition of garnet, only Wright et al. (1995) and Carlson et al. (2014) have carried out computer simulation methods to calculate $\mathrm{O}$ and trace element diffusivity in garnet so far.

\section{Review of available diffusion data}

In this section, we will discuss the experimental results on diffusion of various elements in garnet (including self-, tracer-, and interdiffusion) at high pressure. In Figs. 1, 2, 3, 4 and Table 1, we compile more data than what is covered here.

\subsection{Self-diffusion ( $\mathrm{Si}, \mathrm{O}, \mathrm{Mg}, \mathrm{Fe}, \mathrm{Mn}, \mathrm{Ca})$}

\subsubsection{Silicon diffusion}

To date, only Shimojuku et al. (2014) have determined the pressure and temperature dependencies of $\mathrm{Si}$ volume diffusion rates in a single crystal of $\mathrm{Pyp}_{75} \mathrm{Alm}_{15} \mathrm{Gr}_{10}$ garnet at 6-25 GPa and $1673-2073 \mathrm{~K}$ using the ${ }^{29} \mathrm{Si}$ tracer diffusion method. They obtained the activation volume $\left(4.7 \pm 0.5 \mathrm{~cm}^{3} / \mathrm{mol}\right)$ for Si diffusion. Their results suggest

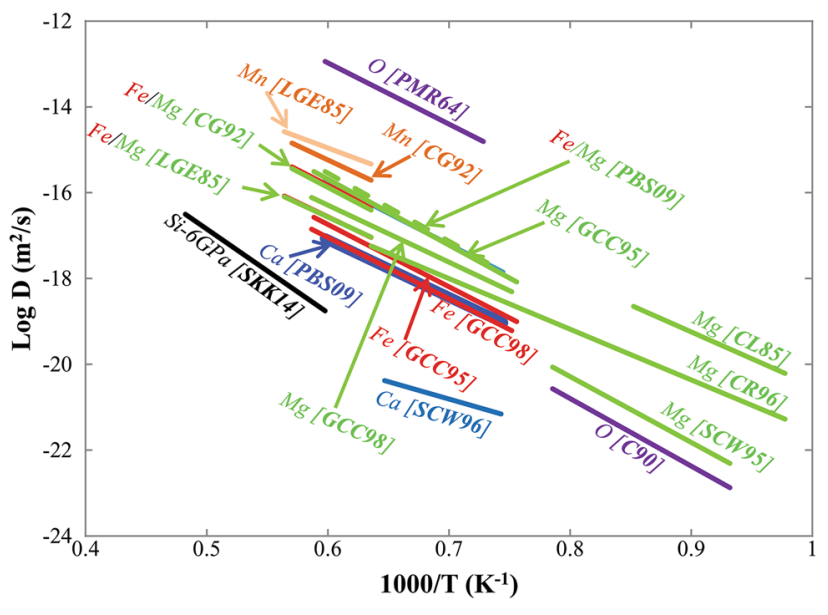

Fig. 1 Arrhenius plot summarizing experimental results for selfdiffusion of $\mathrm{O}, \mathrm{Si}, \mathrm{Mg}, \mathrm{Fe}, \mathrm{Ca}, \mathrm{Mn}$ in garnet. Data sources: PMR64 (Paldino et al. 1964), SKK14 (Shimojuku et al. 2014), C90 (Coughlan 1990), CL85 (Cygan and Lasaga 1985), CG92 (Chakraborty and Ganguly 1992), SCW95 (Schwandt et al. 1995), SCW96 (Schwandt et al. 1996), CR96 (Chakraborty and Rubie 1996), GCC95 (Ganguly et al. 1995), GCC98 (Ganguly et al. 1998a), LGE85 (Loomis et al. 1985), PBS09 (Perchuk et al. 2009)

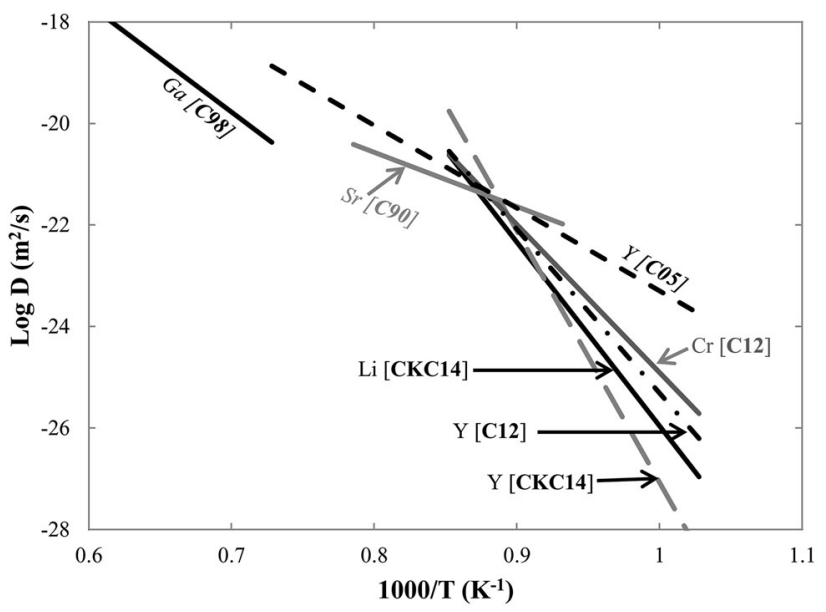

Fig. 2 Arrhenius plot summarizing experimental results for chemical diffusion ( $\mathrm{Li}, \mathrm{Y}, \mathrm{Ga}, \mathrm{Cr}, \mathrm{Sr}$ ) in garnet. Data sources: C90 (Coughlan 1990), C98 (Cherniak 1998), C05 (Cherniak 2005), C12 (Carlson 2012), CKC14 (Cahalan et al. 2014)

that $\mathrm{Si}$ diffusion is the slowest of the major constituent elements in a pyrope-rich garnet and thus controls rates of plastic deformation, and that separation of subducted oceanic crust from an underlying peridotite layer may not occur.

\subsubsection{Oxygen diffusion}

Several experimental studies of oxygen diffusion in garnet have been reported in the past. The first reported oxygen diffusion data are for single crystal and polycrystalline yttrium iron garnet $\left(\mathrm{Y}_{3} \mathrm{Fe}_{5} \mathrm{O}_{12}\right)$ run between 1373 and $1673 \mathrm{~K}$ at $1 \mathrm{~atm}$ by Paldino et al. (1964). The resulting 


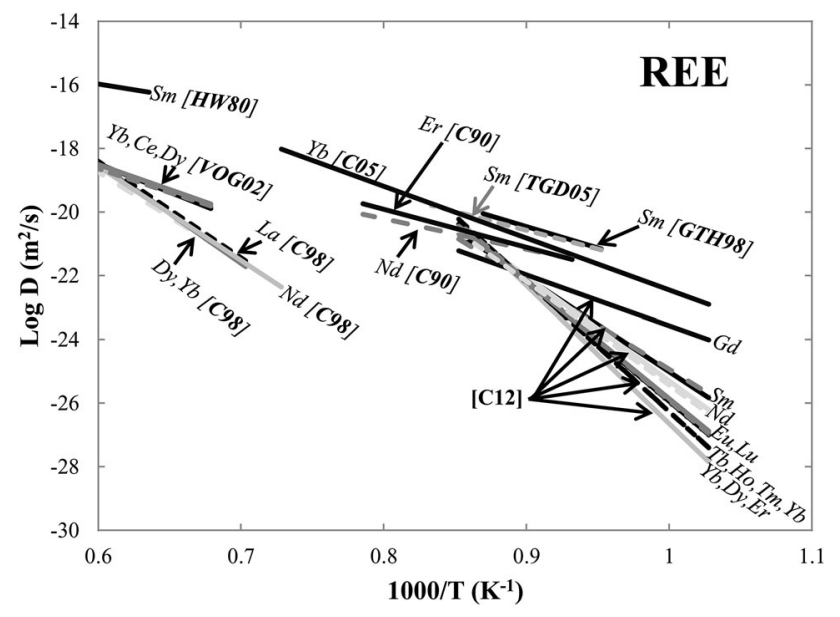

Fig. 3 Arrhenius plot summarizing experimental results for REE diffusion in garnet. Data sources: HW80 (Harrison and Wood 1980), VOG02 (Van Orman et al. 2002), C98 (Cherniak 1998), C05 (Cherniak 2005), C90 (Coughlan 1990), C12 (Carlson 2012), GTH98 (Ganguly et al. 1998b), TGD05 (Tirone et al. 2005)

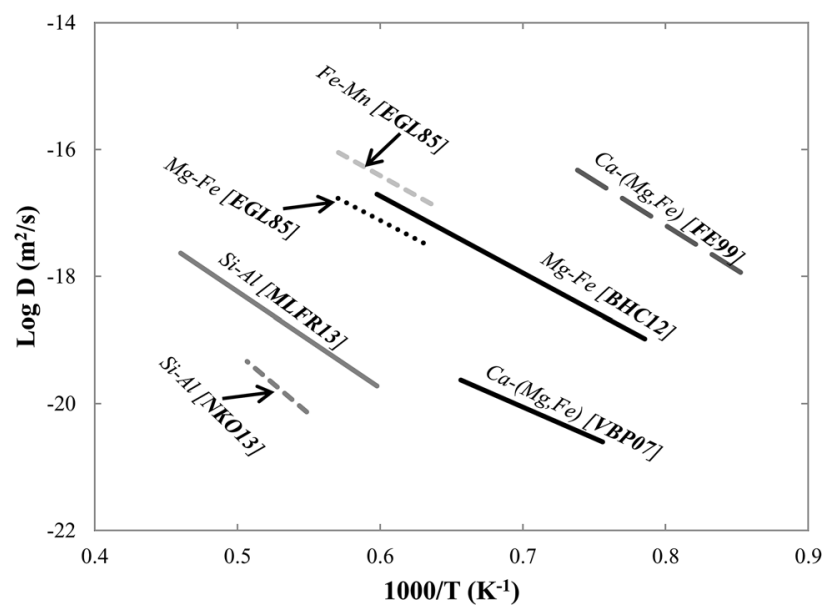

Fig. 4 Arrhenius plot summarizing experimental results for $\mathrm{Fe}-$ $(\mathrm{Mg}, \mathrm{Ca}, \mathrm{Mn}) / \mathrm{Si}-\mathrm{Al}$ interdiffusion in garnet. Data sources: EGL85 (Elphick et al. 1985), MLFR13 (van Mierlo et al. 2013), NKO13 (Nishi et al. 2013), VBP07 (Vielzeuf et al. 2007), BHC12 (Borinski et al. 2012), FE99 (Freer and Edwards 1999)

Arrhenius relations have the form: $D_{\text {Oxy }}=4.0 \times 10^{-5}$ $\exp [-(273.6 \mathrm{~kJ} / \mathrm{mol}) / R T]\left(\mathrm{m}^{2} / \mathrm{s}\right)$. The experiment found no dependence of diffusion rates on the presence of grain boundaries. Freer and Dennis (1982) measured oxygen self-diffusion rates in a natural grossular garnet at $1123 \mathrm{~K}$ and $200 \mathrm{MPa}$ and at $1323 \mathrm{~K}$ and $800 \mathrm{MPa}$ under hydrothermal conditions using ${ }^{18} \mathrm{O}$-enriched water. It is worth noting that their plots of the inverse error function against penetration distance show two distinct linear regions. Freer and Dennis (1982) argued that the near surface region was probably the more reliable one for extracting lattice diffusion rates. However, the small activation energy of $\sim 101 \mathrm{~kJ} / \mathrm{mol}$ obtained from fitting only two data points begged confirmation. The other experimental study of oxygen diffusion in garnet is from Coughlan (1990) for a spess-almandine $\left(\mathrm{Sp}_{0.286} \mathrm{An}_{0.028-}\right.$ $\left.\mathrm{Py}_{0.017} \mathrm{Al}_{0.669}\right)$ composition. Coughlan's diffusion experiments were carried out at $1073-1273 \mathrm{~K}$ and $100 \mathrm{MPa}$ under hydrothermal conditions using ${ }^{18} \mathrm{O}$-enriched water as the tracer source. A linear least square fit to the diffusion coefficients gives an apparent Arrhenius relation with activation energy of $301 \pm 46 \mathrm{~kJ} / \mathrm{mol}$. Later, Wright et al. (1995) investigated oxygen diffusion in grossular garnet by means of computer simulation. The activation energies for $\mathrm{O}$ diffusion in the extrinsic and high-temperature intrinsic regime are 106 and $383 \mathrm{~kJ} / \mathrm{mol}$, respectively. The high activation energy combined with experimentally available diffusion coefficients for $\mathrm{O}$ in garnet suggest that $\mathrm{O}$ mobility is very low at metamorphic temperatures.

\subsubsection{Divalent cation ( $\mathrm{Mg}, \mathrm{Fe}, \mathrm{Mn}, \mathrm{Ca})$ diffusion}

Cygan and Lasaga (1985) determined the tracer diffusion coefficient of ${ }^{25} \mathrm{Mg}$ in a natural pyrope crystal $\left(\operatorname{Prp}_{74}\right.$ $\mathrm{Alm}_{15} \mathrm{Gr}_{10} \mathrm{Uv}_{1}$ ) at temperature of $1023-1173 \mathrm{~K}$ and pressure $0.2 \mathrm{GPa}$. The results obtained at the different temperatures follow the Arrhenius relation, $D_{\mathrm{Mg}}=9.8 \times 10^{-9} \exp [-(239 \pm 16 \mathrm{~kJ} / \mathrm{mol}) / R T]\left(\mathrm{m}^{2} / \mathrm{s}\right)$. Based on the experimental data in Spess-Alm (Alm ${ }_{80} \operatorname{Prp}_{19^{-}}$ $\left.\mathrm{Alm}_{5} \mathrm{Sps}_{95}\right)$ and Alm-Prp ( $\left.\mathrm{Alm}_{68} \operatorname{Prp}_{28}-\mathrm{Alm}_{16} \operatorname{Prp}_{76}\right)$ couples performed by Elphick et al. (1985) at $4 \mathrm{GPa}$ and 1573-1773 K, Loomis et al. (1985) tried to derive tracer diffusion coefficients of $\mathrm{Mg}, \mathrm{Fe}, \mathrm{Mn}$, and $\mathrm{Ca}$ in garnet assuming these coefficients are independent of composition. Furthermore, Chakraborty and Ganguly (1992) carried out additional experiments at high $\mathrm{P}-\mathrm{T}$ conditions $(\sim 1.3$ to 3.5 GPa, $1373-1473 \mathrm{~K}$ ) in a piston-cylinder apparatus using Alm-Sps diffusion couples in graphite capsules to determine the Arrhenius expressions of the self-diffusion coefficients of $\mathrm{Fe}, \mathrm{Mg}$, and $\mathrm{Mn}$, as well as the activation volumes $(\Delta V)$ of diffusion of these species (Fig. 1). $\mathrm{Mg}$ self-diffusion coefficients were also experimentally determined by Schwandt et al. (1995) for natural pyrope-almandine garnet in a 1 atm $\mathrm{CO}-\mathrm{CO}_{2}$ gas-mixing furnace at 1073-1273 K, and determined by Chakraborty and Rubie (1996) for $\mathrm{Mg}$ in natural pyrope and almandine (Alm 38 $\operatorname{Prp}_{50} \mathrm{Gr}_{10} \mathrm{Sps}_{2}$ and $\left.\mathrm{Alm}_{73} \operatorname{Prp}_{21} \mathrm{Gr}_{5} \mathrm{Sps}\right)$ at $1023-1123 \mathrm{~K}$, $0.1 \mathrm{GPa}$, and at $1573 \mathrm{~K}, 8.5 \mathrm{GPa}$, respectively.

Schwandt et al. (1996) reported the self-diffusion coefficient of ${ }^{44} \mathrm{Ca}$ in natural grossular garnet at $0.1 \mathrm{GPa}$, $1073-1273 \mathrm{~K}$, and $f \mathrm{O}_{2}$ defined by the quartz-fayalitemagnetite (QFM) buffer. Their experimental results obtained at the different temperatures yield the Arrhenius relation: $D_{\mathrm{Ca}}=7.2 \times 10^{-16} \exp [-(155 \pm 10 \mathrm{~kJ} / \mathrm{mol}) / R T]$ $\left(\mathrm{m}^{2} / \mathrm{s}\right)$. Ganguly et al. (1998a) carried out multicomponent diffusion couple experiments to retrieve the self-diffusion 


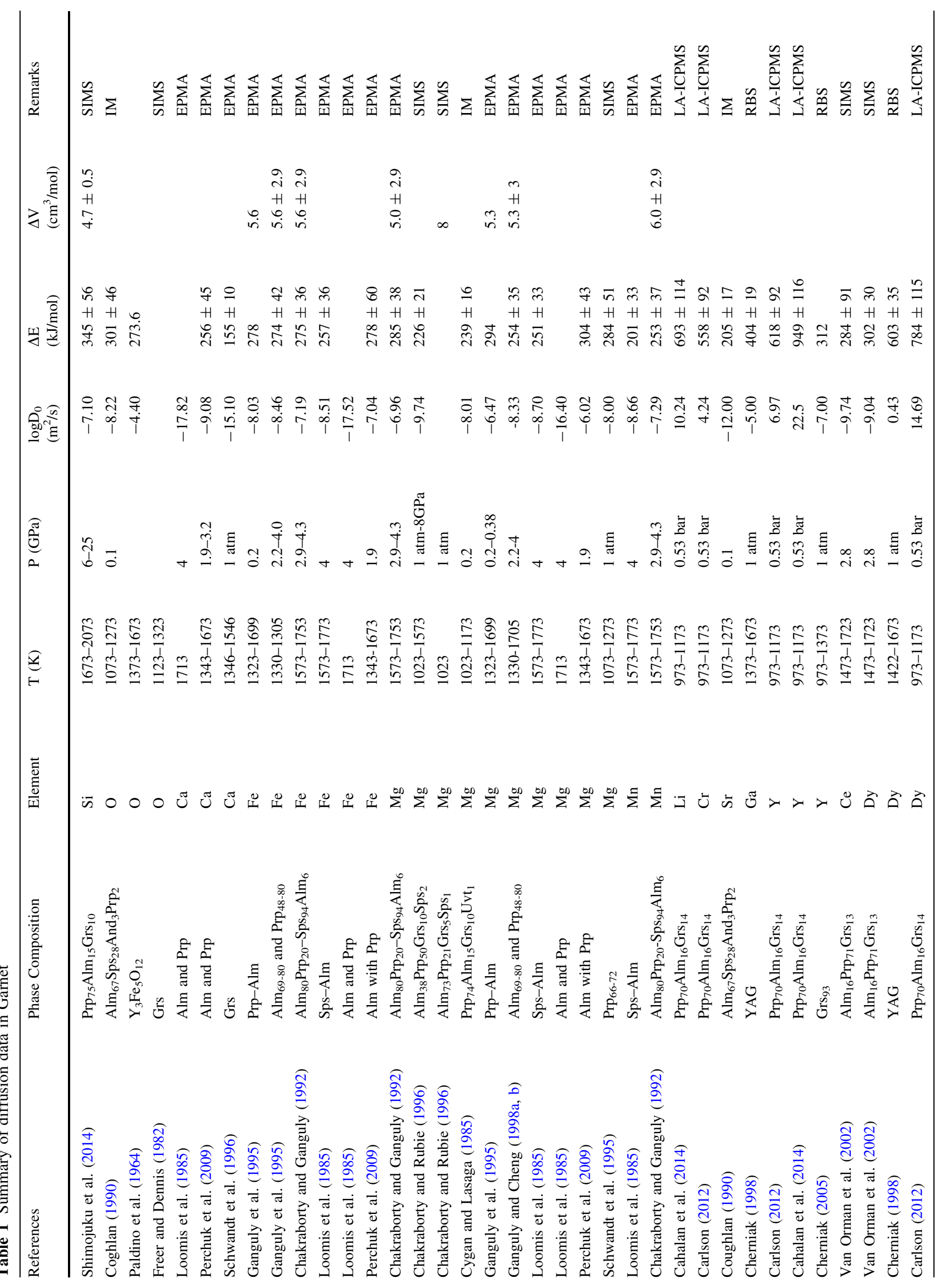




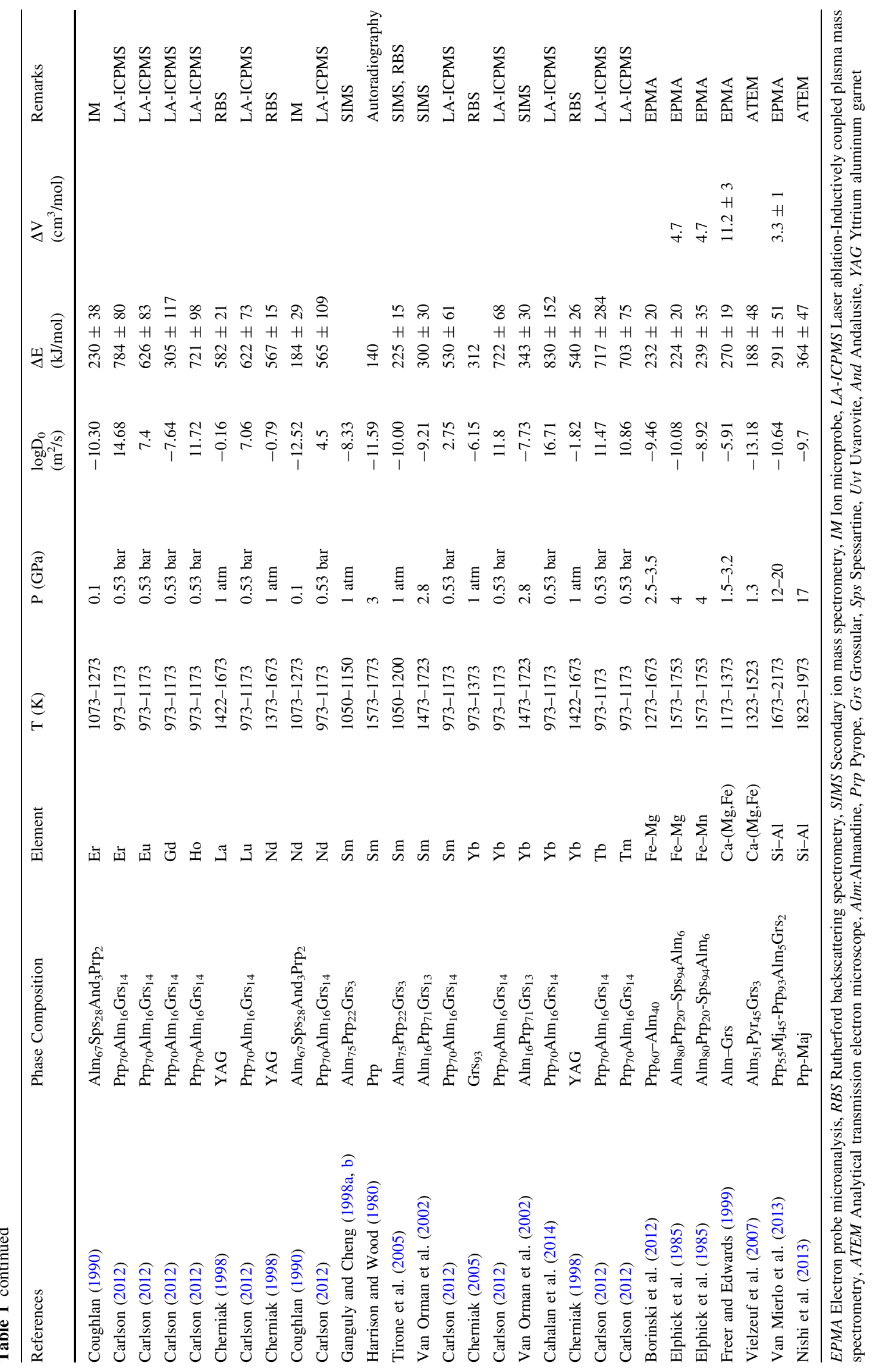


coefficients of the divalent cations $(\mathrm{Fe}, \mathrm{Mg}, \mathrm{Mn}$, and $\mathrm{Ca}$ ) using Mn-poor pyrope-almandine diffusion couples in graphite capsules in a piston-cylinder apparatus under anhydrous conditions at 2.2-4 GPa and 1330-1673 K. When all data are normalized to the same pressure (1 GPa) and to $\mathrm{fO}_{2}$ defined by graphite in the $\mathrm{C}-\mathrm{O}$ system, lower temperature extrapolation of the Arrhenian relation for $D_{\mathrm{Mg}}$ is in good agreement with the $\mathrm{Mg}$ tracer diffusion data of Chakraborty and Rubie (1996) and Cygan and Lasaga (1985) at $0.1 \mathrm{GPa}$ and $1023-1173 \mathrm{~K}$ (Fig. 1), but higher by more than one order of magnitude than that obtained by Schwandt et al. (1995). Due to lack of sufficient contrast in the initial compositions of $\mathrm{Mn}$ and $\mathrm{Ca}$ between the two sides of the diffusion couples, Ganguly et al. (1998a) failed to obtain reliable self-diffusion data for $\mathrm{Ca}$ and $\mathrm{Mn}$. More recently, Perchuk et al. (2009) determined self-diffusion coefficients of $\mathrm{Fe}, \mathrm{Mg}$, and $\mathrm{Ca}$ by modeling multicomponent diffusion profiles in Alm-Prp diffusion couples that were annealed at four different $\mathrm{P}-\mathrm{T}$ conditions at 1.9-3.2 GPa and $1343-1673 \mathrm{~K}$ in a piston-cylinder apparatus. As illustrated in Fig. 1, the $D_{\mathrm{Fe}}$ and $D_{\mathrm{Mg}}$ data of Perchuk et al. (2009) in Alm-Prp couples are effectively the same, and are respectively around 0.5 and $1.3 \mathrm{log}$ units greater than those of Ganguly et al. (1998a). On the other hand, the $D_{\mathrm{Ca}}$ data obtained by Perchuk et al. (2009) are in good agreement with those of Ganguly et al. (1998a), but higher than those determined by Schwandt et al. (1996).

\subsection{Trace element diffusion ( $\mathrm{Li}, \mathrm{Y}, \mathrm{Ga}, \mathrm{Cr}, \mathrm{Sr}$, rare earth elements)}

\subsubsection{Li, $\mathrm{Y}, \mathrm{Ga}, \mathrm{Cr}$, Sr diffusion}

Cahalan et al. (2014) determined the diffusion coefficients of $\mathrm{Li}, \mathrm{Y}$, and $\mathrm{Yb}$ at $973-1173 \mathrm{~K}$ and $0.53 \mathrm{GPa}$. Similar diffusivities for $\mathrm{Li}$ and for $\mathrm{Y}$ and $\mathrm{Yb}$ suggest that the transport of $\mathrm{Li}$ through the garnet structure is linked directly to the transport of $\mathrm{Y}+$ REEs. Such a linkage would arise naturally if $\mathrm{Li}$ incorporation into the structure proceeded via a coupled substitution scheme in which $\mathrm{Y}^{3+}$ and trivalent REEs provide local charge balance for $\mathrm{Li}^{+}$to maintain electroneutrality. Recent lattice-dynamics calculations by Carlson et al. (2014) confirm that such coupled substitution schemes are energetically favorable. Cherniak (1998) carried out diffusion experiments for $\mathrm{Ga}$ in yttrium aluminum garnet (YAG). Diffusion profiles were measured with RBS. The resulting Arrhenius relations have the form: $D_{\mathrm{Ga}}=9.96 \times 10^{-6} \exp [-(404 \pm 19 \mathrm{~kJ} / \mathrm{mol}) / R T]\left(\mathrm{m}^{2} / \mathrm{s}\right)$. Coughlan (1990) used isotopic-tracer diffusion methods and SIMS depth-profiling to determine $\mathrm{Sr}$ diffusion in almandine-spessartine garnet $\left(\mathrm{Alm}_{67} \mathrm{Sps}_{28} \mathrm{And}_{3} \mathrm{Pyp}_{2}\right)$ at 0.1 $\mathrm{GPa}$ and $1073-1273 \mathrm{~K}$, which yields $D_{\mathrm{Sr}}=1.0 \times 10^{-12}$ $\exp [-(205 \pm 17 \mathrm{~kJ} / \mathrm{mol}) / R T]\left(\mathrm{m}^{2} / \mathrm{s}\right)$. Very recently, the diffusivities of $\mathrm{Y}$ and $\mathrm{Cr}$ in garnet have been reported by Carlson (2012) at 973-1173 K and 0.53 GPa (Fig. 2). In addition, Wang et al. (1996) determined the diffusivity of the hydrous component in natural pyrope $\left(\mathrm{Py}_{70} \mathrm{Alm}_{16} \mathrm{Gr}_{14}\right)$ using dehydrogenation experiments. They found that the diffusivity of the hydrous component was proportional to the $\mathrm{OH}$ concentration along each profile, indicating the diffusing species is not $\mathrm{OH}$ and is probably a minor or trace species with a concentration proportional to the square of the $\mathrm{OH}$ concentration. However, caution should be exercised in using $\mathrm{OH}$ content in natural pyrope crystals to infer conditions of the source region.

\subsubsection{Trivalent rare earth element diffusion}

Ganguly et al. (1998b) performed tracer diffusion experiments for ${ }^{149} \mathrm{Sm}$ and ${ }^{145} \mathrm{Nd}$ in almandine garnet $\left(\mathrm{Alm}_{75}\right.$ $\left.\operatorname{Prp}_{22} \mathrm{Grs}_{3}\right)$ at $0.1 \mathrm{GPa}$ and $1050-1150 \mathrm{~K}$, with oxygen fugacity $\left(f \mathrm{O}_{2}\right)$ buffered at the $\mathrm{Fe}-\mathrm{FeO}$ equilibrium, using SIMS depth-profiling to measure concentration gradients. Both rare earth isotopes were found to have almost the same diffusivity, which is similar to the diffusivity of $\mathrm{Mg}$ in garnet of similar composition. Diffusion rates of four REEs (La, Nd, Dy, $\mathrm{Yb}$ ) have also been investigated in YAG by Cherniak (1998) (Fig. 3). Sources of diffusant were mixtures of alumina and REE oxides for REE diffusion and RBS was used to measure concentration gradients. On the other hand, two earlier studies (Harrison and Wood 1980; Coughlan 1990) of Sm and Nd diffusion in natural aluminosilicate garnets reported both faster diffusivities and lower activation energies than those measured for REE transport in YAG (Cherniak 1998), but experimental conditions and details reported in both cases indicate that garnets may not have been stable throughout the duration of anneals. It is thus possible that diffusion might not have been the sole process occurring during these experiments.

Van Orman et al. (2002) determined diffusion rates of $\mathrm{Ce}, \mathrm{Sm}$, Dy, and $\mathrm{Yb}$ in a pyrope-almandine-grossular garnet $\left(\operatorname{Prp}_{71} \mathrm{Alm}_{16} \mathrm{Grs}_{13}\right)$ at $1473-1723 \mathrm{~K}$ and $2.8 \mathrm{GPa}$, and $f \mathrm{O}_{2}$ corresponding to the graphite-oxygen equilibrium in a piston-cylinder apparatus, employing SIMS depthprofiling to measure concentration gradients. Their data revealed similar activation energies $(\sim 300 \mathrm{~kJ} / \mathrm{mol})$ for $\mathrm{Ce}$, $\mathrm{Sm}, \mathrm{Dy}$, and $\mathrm{Yb}$ diffusion in garnet, suggesting a weak dependence of the diffusivities of trivalent REEs on ionic radius. The resulting diffusion coefficients, when extrapolated to the temperatures of the Ganguly et al. (1998b) study at the same pressure, are several orders of magnitude smaller, and activation energies are substantially higher (Fig. 3); both effects should be due at least in part to the large difference in experimental pressures and compositions. In order to investigate the dependence of the diffusivities of the trivalent REE ions on their ionic radius and 
the composition of the garnet matrix, Tirone et al. (2005) redetermined the diffusion coefficient of $\mathrm{Sm}$ in almandine garnet $\left(\mathrm{Alm}_{75} \mathrm{Pyr}_{22} \mathrm{Grs}_{3}\right)$ as a function of temperature $(1050-1200 \mathrm{~K})$ at $0.1 \mathrm{GPa}$ and $f \mathrm{O}_{2}$ corresponding to that of $\mathrm{Fe}-\mathrm{FeO}$ buffer. Note that the REE diffusion coefficients determined by Tirone et al. (2005) are much higher than those of Van Orman et al. (2002). It is possible that the pressure and compositional dependence of the diffusivities of the REEs are somewhat different between these two data sets. Later, Cherniak (2005) examined diffusion of $\mathrm{Yb}$ and $\mathrm{Y}$ in grossular garnet $\left(\mathrm{Grs}_{93}\right)$ at $973-1373 \mathrm{~K}, 0.1 \mathrm{GPa}$, and with $f \mathrm{O}_{2}$ buffered by either iron-wustite (IW) or QFM. The $\mathrm{Y}$ and $\mathrm{Yb}$ distributions in the garnet were profiled with RBS. Diffusion coefficients for $\mathrm{Yb}$ and $\mathrm{Y}$ from experiments buffered at IW are about an order of magnitude slower than under QFM-buffered conditions. The similar diffusivities found for $\mathrm{Yb}$ and $\mathrm{Y}$ are consistent with earlier observations by Van Orman et al. (2002) that show little variation in diffusivities among the REEs in pyrope.

Carlson (2012) reported Nd, Sm, Eu, Gd, Tb, Dy, Ho, $\mathrm{Er}, \mathrm{Tm}, \mathrm{Yb}$, and Lu diffusion in garnet at 973 to $1173 \mathrm{~K}$, $0.53 \mathrm{GPa}$. Their experiments returned diffusion coefficients for these trivalent REEs cations $0.5-1.5 \log _{10}$ units smaller than those for major divalent cations ( $\mathrm{Fe}, \mathrm{Mg}, \mathrm{Ca}, \mathrm{Mn}$ ) measured in the same crystals (Carlson 2006), but diffusivities for trivalent cations are all equal to one another within $\pm 0.25 \log _{10}$ unit and in good agreement with those of Cahalan et al. (2014) (Fig. 3).

\subsubsection{Interdiffusion ( $\mathrm{Fe} / \mathrm{Mg}-\mathrm{Ca} / \mathrm{Mn}, \mathrm{Si}-\mathrm{Al}$ )}

Elphick et al. (1985) reported the first credible results on divalent cation diffusion kinetics in garnet at high $\mathrm{P}-\mathrm{T}$ conditions (3-4 GPa, 1300-1500 ${ }^{\circ} \mathrm{C}$ ), using diffusion couples made from natural garnet crystals. Their data indicate that the multicomponent diffusion kinetics in garnet strongly depend on $\mathrm{Mg} / \mathrm{Mn}$ ratio. Consequently, $\mathrm{Fe}-$ $\mathrm{Mg}$ interdiffusion is one order of magnitude slower than $\mathrm{Fe}-\mathrm{Mn}$ interdiffusion in garnet. Freer and Edwards (1999) performed $\mathrm{Ca}-(\mathrm{Fe}, \mathrm{Mg})$ interdiffusion experiments between grossular and almandine single crystals, and measured the activation volume at $1273 \mathrm{~K}$ between 1.5 and $3.2 \mathrm{GPa}$. They found a very high value $\left(11.2 \mathrm{~cm}^{3} / \mathrm{mol}\right)$ for the activation volume, for which they could not offer a plausible explanation. Vielzeuf et al. (2007) determined quasibinary $\mathrm{Ca}-(\mathrm{Fe}, \mathrm{Mg})$ interdiffusion coefficients in garnet-as if $\mathrm{Fe}$ and $\mathrm{Mg}$ constitute a single component-from the results of diffusion couple experiments in a piston-cylinder apparatus at $1.5-3.2 \mathrm{GPa}, 1173-1373 \mathrm{~K}, f \mathrm{O}_{2}$ : IW buffer and $1.3 \mathrm{GPa}, 1323-1523 \mathrm{~K}, f \mathrm{O}_{2}$ : $\leq$ graphite- $\mathrm{O}_{2}$ buffer, respectively. The interdiffusion coefficients of $\mathrm{Ca}-(\mathrm{Fe}, \mathrm{Mg})$ in garnet reported by Vielzeuf et al. (2007) are much lower than those obtained by Freer and Edwards (1999) (Fig. 4).
This observation suggests that the compositional dependence of the quasi-binary interdiffusion coefficient is quite large. Borinski et al. (2012) carried out diffusion couple experiments (2.5-3.5 GPa and 1533-1673 K) to determine $\mathrm{Fe}-\mathrm{Mg}$ interdiffusion coefficients in garnet in a pistoncylinder apparatus using natural pyrope and almandine crystals. Also, Borinski et al. (2012) developed and tested a numerical method to calculate best-fit diffusion coefficients from experimentally induced concentration profiles. Consequently, diffusion coefficients $D_{\mathrm{Fe}-\mathrm{Mg}}$ retrieved using the two kinds of models do not differ from experimentally reported data for most natural garnet compositions. Diffusivities retrieved by Freer and Edwards (1999) are higher than for other experimental data (Elphick et al. 1985; Borinski et al. 2012; Vielzeuf et al. 2007) (Fig. 4).

Recently, $\mathrm{Si}-\mathrm{Al}$ interdiffusion rates between pyrope and majoritic garnet have been determined by Nishi et al. (2013) and van Mierlo et al. (2013). DSi-Al reported by Nishi et al. (2013) is one order of magnitude lower than that determined by van Mierlo et al. (2013) (Fig. 4). This discrepancy may be caused by the different starting samples used for diffusion couples and by the different oxygen buffer between these two experiments. They found that $\mathrm{Si}-$ $\mathrm{Al}$ interdiffusion rates in pyrope-rich garnet are low compared to the $\mathrm{Si}$ diffusion rate in other silicate minerals relevant to the deep mantle. Thus, plastic deformation rates in garnet can be estimated from the Si diffusion coefficient. At the relatively low temperatures of the slab, slow kinetics of the pyroxene-garnet transformation due to the low diffusion rate indicate that large low-density metastable regions may exist in the slab, significantly contributing to slab stagnation around the transition region. At the base of the mantle transition zone, stagnant slabs may linger for over $10^{8}$ years due to the sluggish pyroxene-garnet transformation, but may eventually fall into the lower mantle after the completion of the transformation (Nishi et al. 2013; van Mierlo et al. 2013).

\section{Empirical relations and implications}

\subsection{Diffusion compensation law}

The compensation law, which is often called the "isokinetic effect" or Meyer-Neldel rule (MNR), refers to a positive linear relationship between the activation energy $(E)$ and the natural logarithm of the pre-exponential factor $\left(\ln D_{0}\right): \ln D_{0}=\alpha+\beta E$, where the constants $\alpha$ and $\beta$ are specific to a particular material, diffusion mechanism, or diffusing species. In practice, compensation relationships do provide general insight into the ways in which crystal character influences diffusion and help identify anomalies where different diffusion mechanisms may apply. In this 


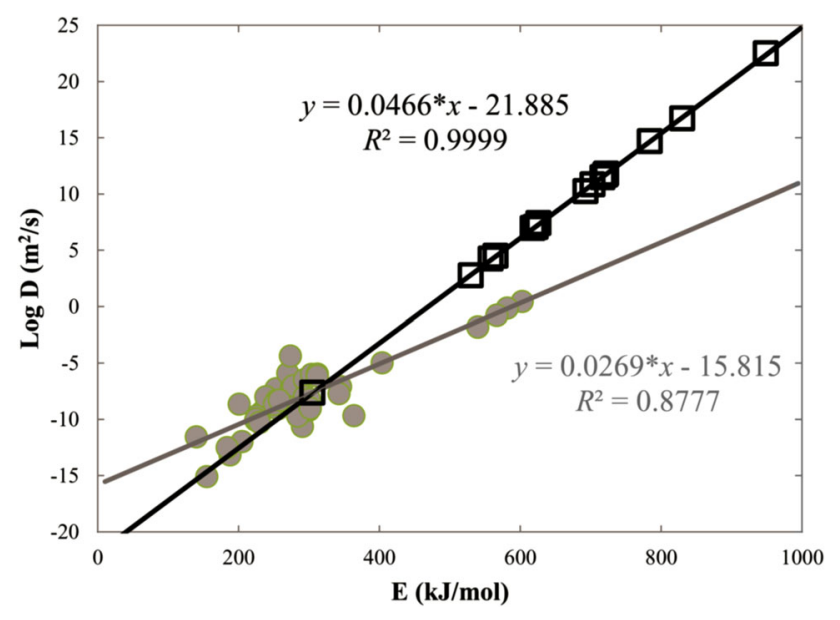

Fig. 5 Compensation plot of the experimentally determined preexponential factor $\left(\log D_{0}\right)$ versus activation energy $(E)$ for various diffusant diffusion in garnet. Solid lines denote the best linear fit to the experimental data. Note that the black and gray lines indicate two regressions to the selected elements; for example, experimental data for black line are reported by Cahalan et al. (2014) for Li + Y+REEs and Carlson (2012) for $\mathrm{Cr}+\mathrm{Y}+\mathrm{REEs}$; experimental data for gray line are from self-diffusion + cations + REEs reported by all the others listed in Table 1. Equations for the compensation lines are also shown

study, an inspection of all diffusion data in garnet reveals two different linear compensation lines (Fig. 5). Obviously, the data on cations and REEs obtained by Cahalan et al. (2014) and Carlson (2012) obey one MNR, but all other data yield another one. As discussed above, the preexponential factor $D_{0}$ and activation energy $E$ for cation ( $\mathrm{Li}, \mathrm{Y}, \mathrm{Cr}$ ) and REE diffusion reported by Cahalan et al. (2014) and Carlson (2012) are much larger than those from other studies (Fig. 3). Carlson (2012) suggested possible reasons for the discrepancy between these two datasets may be differences in host-garnet composition, pressure, and oxygen fugacity.

To date, numerous studies have shown that the MNR is upheld not only for many diffusing species in individual minerals (Hart 1981), but also for a single diffusing species in a wide variety of minerals (Béjina and Jaoul 1997; Zheng and Fu 1998; Zhao and Zheng 2007; Zhang et al. 2010, 2011; Brady and Cherniak 2010; Jones 2014; Zhang and Shan 2015a, b). Recently, based on the observed MNR, a thermodynamic model (the so-called $\mathrm{cB} \Omega$ model) has been successfully applied to predict diffusion coefficients of various elements in silicate minerals (Zhang et al. 2010, 2011; Zhang 2012; Zhang and Shan 2015a, b).

\subsection{Dependence of ionic radius on diffusion parameters}

To investigate the dependence of the diffusivities of cations and REE ions on their ionic radius and the composition of the garnet matrix, Tirone et al. (2005) invoked a sophisticated approach that assigns a dependence on ionic radius not only to the pre-exponential factor in the Arrhenius relation, but also to the activation energy. Recently, Carlson (2012) revisited Tirone's model by adding new diffusion data and assuming an arbitrary activation volume in garnet. Both studies suggested a weak dependence of the diffusivities of trivalent REE on ionic radius. This is in contrast to the significant radius dependence of the diffusivities of REEs in diopside (Van Orman et al. 2001) and zircon (Cherniak et al. 1997).

It is worth noting that to employ Tirone's model, the activation volume of given ions' diffusion must be known. So far, no experimental data are available on the activation volume of REEs and other trivalent cations in garnet. Therefore, we did not use Tirone's model but simply plotted the activation energy $E$ (Fig. 6a) and pre-exponential factor $\log D_{0}$ (Fig. 6b) as a function of the eightfold radius of various ions. It is clear that both $E$ and $\log D_{0}$ for self-diffusion in garnet are nearly independent of ionic radius. Similarly, no marked dependence of $E$ and $\log D_{0}$ on ionic radius was found for cations or REEs in this study. These observations imply that the effect of ionic radius on the diffusion of cations and REEs is small in garnet. Such behavior has been plausibly explained by a novel diffusion mechanism for cations and REEs that links their mobility to diffusion of $\mathrm{Al}$ on the sublattice of octahedral sites in garnet (Carlson 2012).

\subsection{Geological applications of experimental diffusion data}

The wide ranging geological applications of garnet diffusion data have been reviewed by several labs (Ganguly 2002, 2010; Tirone et al. 2005). Diffusion kinetic modeling of the major element compositional zoning of garnets lead to important constraints on the time scales of metamorphic processes such as heating and cooling rates, from which one may infer burial and exhumation rates, respectively (Ganguly et al. 2000). In addition to providing an important constraint on the depth of the source region of a basaltic magma, the REE pattern of basaltic magma with garnet signature is often used to infer the extent of partial melting in the Earth's mantle. Garnets in mantle-derived xenoliths sometimes show REE compositional differences between the core and rim of individual grains. With the aid of diffusion data for REEs in garnet, these properties may be modeled to constrain residence time of garnets within an external magma source that might have come into contact with them in the Earth's mantle (Tirone et al. 2005). For further discussion of the above applications, the reader is referred to the review articles of Ganguly $(2002,2010)$ and to the original papers. Here we merely outline some selected additional 

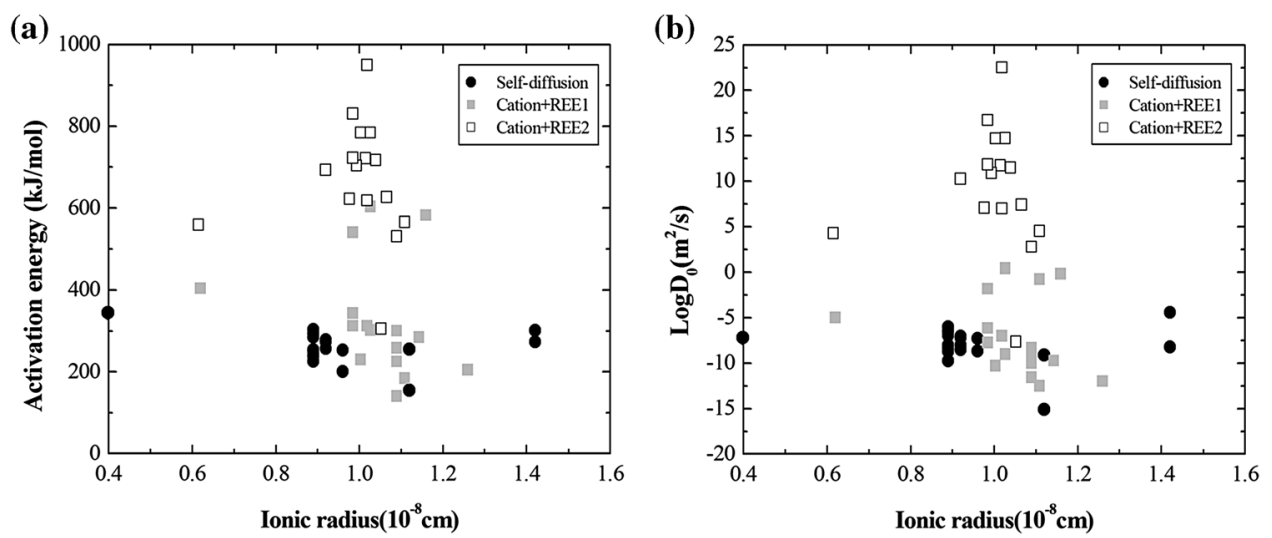

Fig. 6 Plot of the activation energy $E$ (a) and preexponential factor $\log D_{0}$ (b) versus the eightfold radius of various diffusants. Radii from Shannon (1976). Note that, the data for self-diffusion of O, Si, Mg, Fe, Ca, Mn are listed in Fig. 1; the data for cation + REE1 are from all the others except for self-diffusion and cation + REE2; the data for cation + REE2 are from Cahalan et al. (2014) and Carlson (2012)

applications of diffusion data in garnet to illustrate how these data enable us to provide quantitative constraints on a large spectrum of geological processes and problems:

1. Close temperature of Sm-Nd decay system and Lu-Hf geochronology of garnets in metamorphic rocks (Ganguly et al. 1998a; Van Orman et al. 2002; Tirone et al. 2005; Ganguly 2010; Borinski et al. 2012).

2. Cooling rates of metamorphic rocks: diffusion modeling of garnet versus geochronological constraints (Chakraborty and Ganguly 1992; Ganguly et al. 1995, 1998b; Ganguly 2010).

3. Time scales of tectono-metamorphic processes in collisional environments: records in garnet zoning (Ganguly et al. 1998a; Ganguly 2002).

4. Modeling multicomponent diffusing profiles using effective binary diffusion formation (Ganguly et al. 1996; Ganguly 2010).

5. Modeling partially modified growth zoning of garnets in metamorphic rocks (Chakraborty and Ganguly 1992; Ganguly 2010).

6. Subduction and exhumation rates (Ganguly et al. 2000; Ganguly 2010; Tirone and Ganguly 2010; Nishi et al. 2013; van Mierlo et al. 2013).

7. REE zoning in garnet from lherzolite xenolith (Tirone et al. 2005).

\section{Concluding remarks}

The accomplishments of the geoscience community in measuring and interpreting diffusion data in garnets over the last several decades are quite impressive. Our database for garnets now contains 65 diffusion datasets for 27 elements with self-, chemical-, and inter-diffusion. One important general conclusion is that the diffusion coefficients of any elements in garnets strongly depend on composition as well as pressure, temperature, and other chemical parameters (such as oxygen fugacity and water fugacity). Through the data collected in this paper, it is possible to look for empirical relationships and to test models against measured diffusivities.

With the new experimental tools that are just becoming available (thin film technology, analytical tools such as NanoSIMS, field emission electron microprobes, and analytical transmission electron microscopes), determination of more accurate diffusion coefficients for a wide range of elements in a wider range of minerals will be possible (Chakraborty 2008). Notably, for many geoscience applications in modeling studies, it is now possible to interpolate, rather than extrapolate, diffusion coefficients measured in the laboratory. Nevertheless, inconsistencies are often found between diffusion rates of the same element in garnet reported by different workers under similar conditions; for example, REE diffusion measured by Carlson (2012) and others (Fig. 3) and Si-Al/Ca-(Fe,Mg) interdiffusion (Fig. 4). Consequently, those who want to apply such data to natural systems are in the unfortunate and unsatisfying position of having to choose between competing laboratory "truths," often without the knowledge or abilities to make sensible choices. In some cases, the choices made can lead to dramatically different conclusions about the state of the Earth. Therefore, great efforts should be made to eliminate the experimental uncertainties and develop theoretical models to reconcile the compatible data in future.

Although significant progress has been made on diffusion in garnets over the past several decades, some significant issues remain challenging, such as the effect of water fugacity on cation diffusion kinetics in garnet. It has been recognized that the presence of water in the system of interest can have a significant influence on diffusion in many 
geologic materials (Watson and Baxter 2007), even in trace amounts. We note that all diffusion experiments were carried out with natural samples that always have some dissolved water. Thus, it is likely that the effect of water has been absorbed in the retrieved values of the diffusion coefficients in the nominally anhydrous experiments. On the other hand, first-principle calculation or molecular dynamics simulation of defect states and migration in realistic garnet with complex composition will contribute significantly to our understanding of diffusion behavior. On a different scale, models of reaction with diffusion and other moving boundary problems solved numerically will considerably expand the scope of diffusion modeling. Unfortunately, except for Wright et al. (1995) and Carlson et al. (2014), no such study has been reported in garnet to date.

Acknowledgements This study was supported by the Strategic Priority Research Program (B) of the Chinese Academy of Sciences (XDB 18010401), the 1000Plan Program for Young Talents and Hundred Talent Program of CAS, and NSF of China (41303048). We would like to thank three anonymous reviewers for constructive comments, and the handling editor Dr. Binbin Wang.

\section{Compliance with ethical standards}

Conflict of interest The authors declare no competing financial interests.

Open Access This article is distributed under the terms of the Creative Commons Attribution 4.0 International License (http://creative commons.org/licenses/by/4.0/), which permits unrestricted use, distribution, and reproduction in any medium, provided you give appropriate credit to the original author(s) and the source, provide a link to the Creative Commons license, and indicate if changes were made.

\section{References}

Béjina F, Jaoul O (1997) Silicon diffusion in silicate minerals. Earth Planet Sci Lett 153:229-238

Béjina F, Jaoul O, Liebermann RC (2003) Diffusion in minerals at high pressure: a review. Phys Earth Planet Inter 139:3-20

Borinski SA, Hoppe U, Chakraborty S, Ganguly J, Bhowmik SK (2012) Multicomponent diffusion in garnets I: general theoretical considerations and experimental data for $\mathrm{Fe}-\mathrm{Mg}$ systems. Contrib Mineral Petrol 164:571-586

Brady JB (1995) Diffusion data for silicate minerals, glasses, and liquids. In: Ahrens TJ (ed) Mineral physics \& crystallography: a handbook of physical constants. AGU, Washington, pp 269-290

Brady JB, Cherniak DJ (2010) Diffusion in minerals: an overview of published experimental data. Rev Mineral Geochem 72:899-920

Cahalan RC, KElly ED, CaRlso WD (2014) Rates of Li diffusion in garnet: coupled transport of $\mathrm{Li}$ and $\mathrm{Y}+$ REEs. Am Mineral 99(8-9):1676-1682

Carlson WD (2006) Rates of $\mathrm{Fe}, \mathrm{Mg}, \mathrm{Mn}$ and $\mathrm{Ca}$ diffusion in garnet. Am Mineral 91:1-11

Carlson WD (2012) Rates and mechanism of Y, REE, and $\mathrm{Cr}$ diffusion in garnet. Am Mineral 97:1598-1618

Carlson WD, Gale JG, Wright K (2014) Incorporation of Y and REEs in aluminosilicate garnet: energetics from atomistic simulation. Am Mineral 99:1022-1034
Chakraborty S (1997) Rates and mechanisms of $\mathrm{Fe}-\mathrm{Mg}$ interdiffusion in olivine at 980-1300 C. J Geophys Res 102(B6):12317-12331

Chakraborty S (2008) Diffusion in solid silicates-a tool to track timescales of processes comes of age. Annu Rev Earth Planet Sci $36: 153-190$

Chakraborty S (2010) Diffusion coefficients in olivine, wadsleyite and ringwoodite. Rev Mineral Geochem 72:603-639

Chakraborty S, Ganguly J (1992) Cation diffusion in alumino-silicate garnets: experimental determination in spessartine-almandine diffusion couples, evaluation of effective binary diffusion coefficients, and applications. Contrib Miner Petrol 111:74-86

Chakraborty S, Rubie DC (1996) Mg tracer diffusion in aluminosilicate garnets at $750-850{ }^{\circ} \mathrm{C}, 1 \mathrm{~atm}$. and $1300{ }^{\circ} \mathrm{C}, 8.5 \mathrm{GPa}$. Contrib Miner Petrol 122:406-414

Chakraborty S, Farver JR, Yund RA, Rubie DC (1994) Mg tracer diffusion in synthetic forsterite and San Carlos olivine as a function of $\mathrm{P}, \mathrm{T}$ and $f \mathrm{O}_{2}$. Phys Chem Miner 21:489-500

Cherniak DJ (1993) Lead diffusion in titanite and preliminary results on the effects of radiation damage on $\mathrm{Pb}$ transport. Chem Geol 110:177-194

Cherniak DJ (1998) Rare earth element and gallium diffusion in yttrium aluminum garnet. Phys Chem Mineral 26:156-163

Cherniak DJ (2005) Yb and Y diffusion in grossular garnet. Geochim Cosmochim Acta 69:405

Cherniak DJ, Dimanov A (2010) Diffusion in pyroxene, mica, and amphi-bole. Rev Mineral Geochem 72:641-690

Cherniak DJ, Hanchar JM, Watson EB (1997) Rare earth diffusion in zircon. Chem Geol 134:289-301

Cherniak DJ, Hervig R, Koepke J, Zhang Y, Zhao D (2010) Analytical methods in diffusion studies. Rev Mineral Geochem 72:107-169

Coughlan RAN (1990) Studies in diffusional transport: grain boundary transport of oxygen in feldspars, strontium and the REE's in garnet, and thermal histories of granitic intrusions in southcentral Maine using oxygen isotopes. $\mathrm{PhD}$ thesis, Brown University, Providence

Cygan RT, Lasaga AC (1985) Self-diffusion of magnesium in garnet at $750-900{ }^{\circ} \mathrm{C}$. Am J Sci $285: 328-350$

Dohmen R, Chakraborty S (2007) Fe-Mg diffusion in olivine II: point defect chemistry, change of diffusion mechanisms and a model for calculation of diffusion coefficients in natural olivine. Phys Chem Miner 34:409-430

Elphick SC, Ganguly J, Loomis TP (1985) Experimental determination of cation diffusivities in aluminosilicate garnets: I. Experimental methods and interdiffusion data. Contrib Mineral Petrol 90:36-44

Farver JR (2010) Oxygen and hydrogen diffusion in minerals. Rev Mineral Geochem 72(1):447-507

Freer R (1981) Diffusion in silicate minerals and glasses: a data digest and guide to the literature. Contrib Mineral Petrol 76(4):440-454

Freer R, Dennis PF (1982) Oxygen diffusion studies. I. A preliminary ion microprobe investigation of oxygen diffusion in some rockforming minerals. Mineral Mag 45:179-192

Freer R, Edwards A (1999) An experimental study of Ca-(Fe, Mg) interdiffusion in silicate garnets. Contrib Mineral Petrol 134(4):370-379

Ganguly J (2002) Diffusion kinetics in minerals: principles and applications to tectono-metamophic processes. EMU Notes Mineral 4:271-309

Ganguly J (2010) Cation diffusion kinetics in aluminosilicate garnets and geological applications. Rev Mineral Geochem 72(1):559-601

Ganguly J, Chakraborty S, Cheng W (1995) Self diffusion of $\mathrm{Fe}^{2+}$ and $\mathrm{Mg}$ in pyrope-almandine garnets; experimental determination, applications to cooling rate of granulites and comparison 
with geochronological data. EOS Trans Am Geophys Union $76: 703$

Ganguly J, Chakraborty S, Sharp T, Rumble D (1996) Constraint on the time scale of biotite-grade metamorphism during Acadian orogeny from a natural gernat-garnet diffusion couple. Am Mineral 81:1208-1216

Ganguly J, Cheng W, Chakraborty S (1998a) Cation diffusion in aluminosilicate garnets; experimental determination in pyropealmandine diffusion couples. Contrib Mineral Petrol 131:171-180

Ganguly J, Tirone M, Hervig M (1998b) Diffusion kinetics of samarium and neodymium in garnet, and a method for determining cooling rates of rocks. Science 281:805-807

Ganguly J, Cheng W, Dasgupta S, Neogi S (2000) Exhumation history of a section of the Sikkim Himalayas, India: records in metamorphic mineral equilibria and compositional zoning of garnet. Earth Planet Sci Lett 183:471-486

Harrison WJ, Wood BJ (1980) An experimental investigation of the partitioning of REE between garnet and liquid with reference to the role of defect equilibria. Contrib Mineral Petrol 72:145-155

Hart SR (1981) Diffusion compendation in natural silicates. Geochim Cosmochim Acta 45(3):279-291

Hier-Majumder S, Anderson IM, Kohlstedt DL (2005) Influence of protons on $\mathrm{Fe}-\mathrm{Mg}$ interdiffusion in olivine. J Geophys Res 110:B02202

Irifune T, Ringwood AE (1987) Phase transformations in primitive MORB and pyrolite compositions to $25 \mathrm{GPa}$ and some geophysical implications. In: High-pressure research in mineral physics: a volume in honor of Syun-iti Akimoto, pp 231-242

Jaoul O, Bertran-Alvarez Y, Liebermann RC, Price GD (1995) Fe$\mathrm{Mg}$ interdiffusion in olivine up to $9 \mathrm{GPa}$ at $T=600-900{ }^{\circ} \mathrm{C}$; experimental data and comparison with defect calculations. Phys Earth Planet Inter 89:199-218

Jones AG (2014) Compensation of the Meyer-Neldel compensation law for $\mathrm{H}$ diffusion in minerals. Geochem Geophys Geosyst 15:2616-2631

Loomis TP, Ganguly J, Elphick SC (1985) Experimental determination of cation diffusivities in aluminosilicate garnets; II, Multicomponent simulation and tracer diffusion coefficients. Contrib Mineral Petrol 90:45-51

Mehrer H (2007) Diffusion in solids: fundamentals, methods, materials, diffusion-controlled processes. Springer, Berlin

Mueller T, Watson EB, Harrison TM (2010) Applications of diffusion data to high-temperature earth systems. Rev Mineral Geochem 72(1):997-1038

Nishi M, Kubo T, Ohfuji H, Kato T, Nishihara Y, Irifune T (2013) Slow $\mathrm{Si}-\mathrm{Al}$ interdiffusion in garnet and stagnation of subducting slabs. Earth Planet Sci Lett 361:44-49

Paldino AE, Maguire EA, Rubin LG (1964) Oxygen ion diffusion in single-crystal and polycrystalline yttrium iron garnet. J Am Ceram Soc 47:280-282

Perchuk AL, Burchard M, Schertl HP, Maresch WV, Gerya TV, Bernhardt HJ, Vidal O (2009) Diffusion of divalent cations in garnet. Contrib Mineral Petrol 157:573-592

Pigott JS, Wright K, Gale JD, Panero WR (2015) Calculation of the energetics of water incorporation in majorite garnet. Am Mineral 100(5-6): 1065-1075

Schwandt CS, Cygan RT, Westrich HR (1995) Mg self-diffusion in pyrope garnet. Am Mineral 80:483-490

Schwandt CS, Cygan RT, Westrich HR (1996) Ca self-diffusion in grossular garnet. Am Mineral 81:448-451

Shannon RT (1976) Revised effective ionic radii and systematic studies of interatomic distances in halides and chalcogenides. Acta Cryst A 32(5):751-767

Shewmon PG (1963) Diffusion in solids. McGraw-Hill, New York

Shimojuku A, Kubo T, Kato T, Yoshino T, Nishi M, Nakamura T, Okazaki R, Kakazu Y (2014) Effects of pressure and temperature on the silicon diffusivity of pyrope-rich garnet. Phys Earth Planet Inter 226:28-38

Tilley RJD (2008) Defects in solids. Wiley, Hoboken

Tirone M, Ganguly J (2010) Garnet compositions as recorders of $P-T$ $t$ history of metamorphic rocks. Gondwana Res 18(1):138-146

Tirone M, Ganguly J, Dohmen R, Langenhorst F, Hervig R, Becker HW (2005) Rare earth diffusion kinetics in garnet; experimental studies and applications. Geochim Cosmochim Acta 69:2385-2398

van Mierlo WL, Langenhorst F, Frost DJ, Rubie DC (2013) Stagnation of subducting slabs in the transition zone due to slow diffusion in majoritic garnet. Nat Geosci 6:400-403

Van Orman JA, Grove TL, Shimizu N (2001) Rare earth element diffusion in diopside: influence of temperature, pressure and ionic radius, and an elastic model for diffusion in silicates. Contrib Mineral Petrol 141:687-703

Van Orman JA, Grove TL, Shimizu N, Layne GD (2002) Rare earth element diffusion in a natural pyrope single crystal at $2.8 \mathrm{GPa}$. Contrib Mineral Petrol 142:416-424

Van Westrenen W, Allan NL, Blundy JD, Purton JA, Wood BJ (2000) Atomistic simulation of trace element incorporation into garnets-comparison with experimental garnet-melt partitioning data. Geochim Cosmochim Acta 64(9):1629-1639

Vielzeuf D, Baronnet A, Perchuk AL, Laporte D, Baker MR (2007) Calcium diffusivity in alumino-silicate garnets: and experimental and ATEM study. Contrib Mineral Petrol 154:153-170

Wang L, Zhang Y, Essene EJ (1996) Diffusion of the hydrous component in pyrope. Am Mineral 81(5-6):706-718

Wang Z, Hiraga T, Kohlstedt DL (2004) Effect of $\mathrm{H}^{+}$on $\mathrm{Fe}-\mathrm{Mg}$ interdiffusion in olivine $(\mathrm{Fe}, \mathrm{Mg})_{2} \mathrm{SiO}_{4}$. Appl Phys Lett $85: 209-211$

Watson EB, Baxter EF (2007) Diffusion in solid-earth systems. Earth Planet Sci Lett 253(3):307-327

Watson EB, Dohmen R (2010) Non-traditional and emerging methods for characterizing diffusion in minerals and mineral aggregates. Rev Mineral Geochem 72(1):61-105

Wright K, Freer R, Catlow CRA (1994) The energetics and structure of the hydrogarnet defect in grossular: a computer simulation study. Phys Chem Mineral 20(7):500-503

Wright K, Freer R, Catlow CRA (1995) Oxygen diffusion in grossular and some geological implications. Am Mineral 80(9-10):1020-1025

Zhang Y (2010) Diffusion in minerals and melts: theoretical background. Rev Mineral Geochem 72(1):5-59

Zhang BH (2012) Diffusion of hydrogen in $(\mathrm{Mg}, \mathrm{Fe})_{2} \mathrm{SiO}_{4}$ and high pressure polymorphs refined by the $\mathrm{cB} \Omega$ model. J Asian Earth Sci 54-55:9-17

Zhang BH (2017) An overview of Fe-Mg interdiffusion in mantle minerals. Surv Geophys. doi:10.1007/s10712-017-9415-5

Zhang BH, Shan SM (2015a) Thermodynamic calculations of Fe-Mg interdiffusion in $(\mathrm{Mg}, \mathrm{Fe})_{2} \mathrm{SiO}_{4}$ polymorphs and perovskite. J Appl Phys 117(5):054906

Zhang BH, Shan SM (2015b) Application of the $\mathrm{cB} \Omega$ model to thecalculation of diffusion parameters of $\mathrm{Si}$ in silicates. Geochem Geophys Geosyst 16:705-718

Zhang BH, Wu XP, Xu JS, Zhou RL (2010) Application of the cB $\Omega$ model for the calculation of oxygen self-diffusion coefficients in minerals. J Appl Phys 108(5):053505

Zhang BH, Wu XP, Zhou RL (2011) Calculation of oxygen selfdiffusion coefficients in $\mathrm{Mg}_{2} \mathrm{SiO}_{4}$ polymorphs and $\mathrm{MgSiO}_{3}$ perovskite based on the compensation law. Solid State Ion 186(1):20-28

Zhao ZF, Zheng YF (2007) Diffusion compensation for argon, hydrogen, lead, and strontium in minerals: empirical relationships to crystal chemistry. Am Mineral 92(2-3):289-308

Zheng YF, Fu B (1998) Estimation of oxygen diffusivity from anion porosity in minerals. Geochem J 32:71-89 